Portland State University

PDXScholar

\title{
A new design approach for numeric-to-symbolic conversion using neural networks
}

Zibin Tang

Portland State University

Follow this and additional works at: https://pdxscholar.library.pdx.edu/open_access_etds

Part of the Electrical and Computer Engineering Commons Let us know how access to this document benefits you.

Recommended Citation

Tang, Zibin, "A new design approach for numeric-to-symbolic conversion using neural networks" (1991). Dissertations and Theses. Paper 4242.

https://doi.org/10.15760/etd.6126

This Thesis is brought to you for free and open access. It has been accepted for inclusion in Dissertations and Theses by an authorized administrator of PDXScholar. Please contact us if we can make this document more accessible: pdxscholar@pdx.edu. 
AN ABSTRACT OF THE THESIS OF Jeanie P. Wagener for the Master of Science in Speech Communication: Speech and Hearing Sciences presented March 6, 1991.

Title: The Correlation Between Correct Verbal and Nonverbal Responses on an Intelligence Test and Expressive Language Test Score.

APPROVED BY THE MEMBERS OF THE THESIS COMMITTEE:

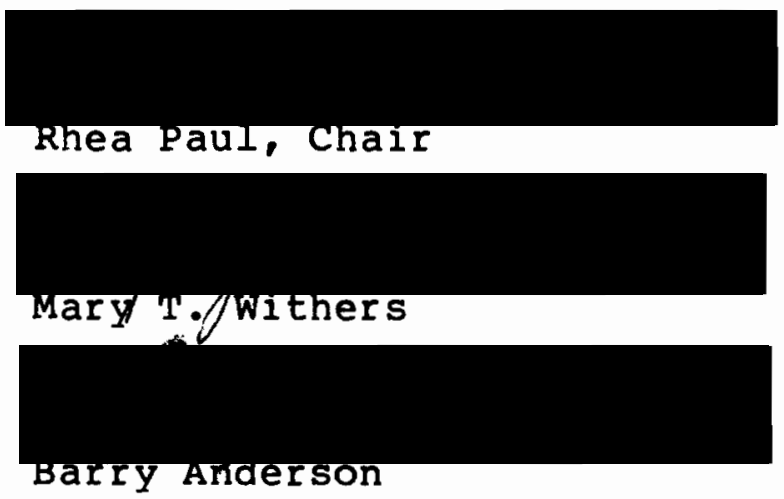

The purpose of this study was to examine the relationship between verbal and nonverbal indices of intelligence from an infant development scale given at approximately two years of age with scores on an expressive language test administered to the same children two years later. The questions this study sought to answer were: (1) is there a difference between the number of verbal and nonverbal items passed at 18-34 months by a group of 
normal children and a group of late talkers, (2) is there a significant relationship between correct verbal and nonverbal responses on an infant development test and scores on an expressive language test two years later in normal children and late talkers, (3) is there a significant relationship between correct verbal receptive items on an infant development test and scores on an expressive language test two years later in normal children and late talkers, and (4) is there a significant relationship between correct expressive responses on an infant development test and expressive scores two years later in the normal children and the group of later talkers.

Fifty-one subjects participated in this study, 25 children with normal language and 26 children considered to be late talkers. These children are part of a longitudinal study presently going on at portland state University.

The instruments used to acquire data for this study were the Bayley Infant Development Scale and the Test of Language Development.

A significant difference between the number of correct verbal items passed on the infant development scale was found, but no significance was found between the number of nonverbal items passed between the two groups. A significant relationship was found between correct verbal 
responses on the infant development scale and the expressive test two years later in the group of late talkers. Nonverbal responses in the group of late talkers failed to reach significance. No significance was found in either verbal or nonverbal responses on the infant intelligence test and the expressive test two years later in the normal group. There was a signficant relationship found between the verbal receptive items on the infant development scale at two years old and the expressive language score at four years old in the group of late talkers. Other correlations failed to reach significance. 
THE CORRELATION BETWEEN CORRECT VERBAL AND NONVERBAL RESPONSES ON AN INTELLIGENCE TEST AND EXPRESSIVE LANGUAGE TEST SCORE

\section{by}

JEANIE P. WAGENER

A thesis submitted in partial fulfillment of the requirements for the degree of

MASTER OF SCIENCE in

SPEECH COMMUNICATION:

SPEECH AND HEARING SCIENCES

Portland State University

1991 
TO THE OFFICE OF GRADUATE STUDIES:

The members of the Committee approve the thesis of Jeanie $P$. Wagener presented March 6, 1991 .

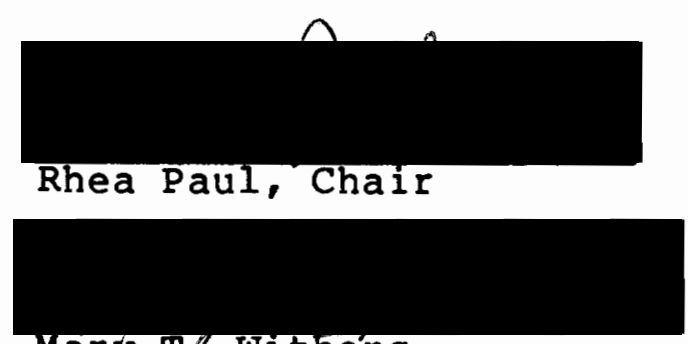

$$
\text { Marky } 17 / \text { withers }
$$

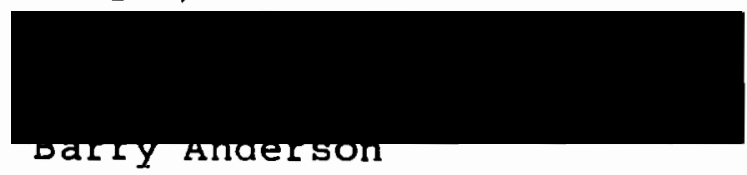

APPROVED:

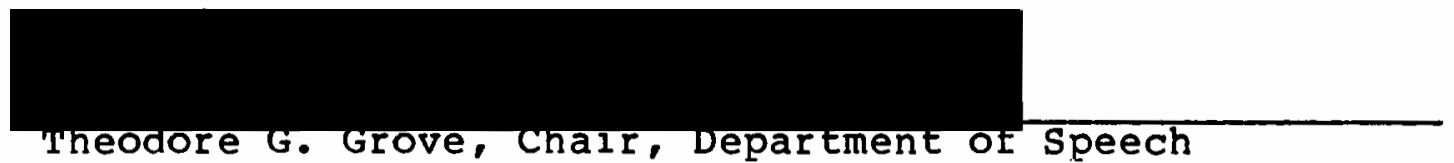
Communication

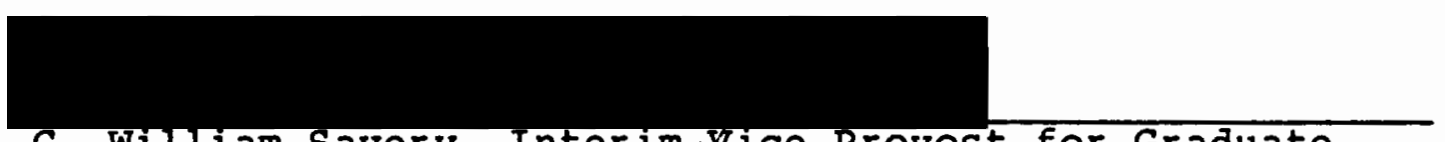

c. William savery, Interimgice provost for Graduate Studies and Research 


\section{ACKNOWLEDGEMENTS}

I would like to thank the members of my committee-Mary T. Withers and Barry Anderson--for their help and encouragement. I would like to extend my sincere gratitude and appreciation to Dr. Rhea Paul, without whom this study would not have been finished. I wish to thank her for her excellent input and unlimited patience in reading this thesis over and over again.

I want to thank my husband, Bill, and my children, Ryan, Christy, and Kalin, for all of their love, support, and patience. I also want to thank my parents and sisters for their support and constant encouragement and for "having no doubt I could do it." 
TABLE OF CONTENTS

PAGE

ACKNOWLEDGEMENTS • • • • • • • • • • • • •

LIST OF TABLES

vi

CHAPTER

I INTRODUCTION AND STATEMENT OF PURPOSE • 1

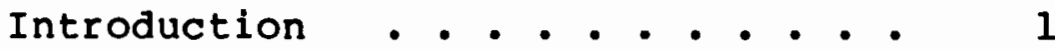

Statement of Purpose . . . . . . 2

Definition of Terms ....... 5

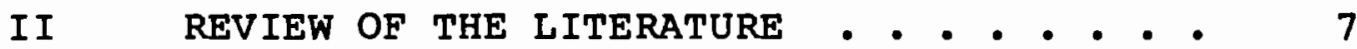

Language and Cognition Research in Normal Development ..... 10

Means-Ends and Word Use Object Permanence and Word Use Symbolic Play and word Use Language and Cognition Research

Cognition in Language Disordered

Children .......... 20

III METHODS AND PROCEDURES . . . . . . 28

Methods . . . . . . . . 28

Subjects: Description at Intake

Screening

Follow-Up Assessment

Instruments

Procedures .......... . 33

Statistical Analysis....... . 34 
PAGE

IV

RESULTS AND DISCUSSION - • • • • • • •

Results

35

Discussion

$\mathrm{V}$

SUMMARY AND IMPLICATIONS • • • • • • •

Summary • • • • • • • • • •

43

Clinical Implications . . . . . 45

Research Implications . . . . . 46

REFERENCES • • • • • • • • • • • • • • • • • • • • 
LIST OF TABLES

TABLE

PAGE

I Summary of Questions . - . . . . . . 5

II Summary of Demographic Data . . . . . . 30

II Mean Scores, Standard Deviations and t-

Values for Responses in Normal Group and Late Talkers . . . . . . . 35

IV Pearson r Coefficient of Correlation

Between Correct Nonverbal and Verbal

Responses at Age Two with the Score

on the Expressive Language Test Two

Years Later for All Subjects . . . .

$V$ Pearson $r$ Coefficient of Correlation

Between Correct Responses on Verbal

Receptive Items and Correct Expressive

Responses on Infant Development Test

With Scores on Expressive Language

Test Two Years Later in Normal

Children . . . . . . . . . . . . 
VI Pearson $r$ Coefficient of Correlation

Between Correct Responses on Verbal

Receptive Items And Correct Expressive

Responses on Infant Development Test

and Scores on Expressive Language

Test Two Years Later in Late Talkers. 


\begin{abstract}
CHAPTER I
INTRODUCTION AND STATEMENT OF PURPOSE
\end{abstract}

\title{
INTRODUCTION
}

According to Bax, Hart, and Jenkins (1980), language delay is the most prevalent developmental problem found in preschool children. Language delays tend to persist for a number of years and are a good predictor of later learning problems (Aram, Ekelman, \& Nation, 1984).

Because of the great variance in the rate of language acquisition in small children, there is very little research to suggest the best age for identifying a language disorder. Concluding that a child has a language delay at an early age when the language problems may resolve naturally, may result in unnecessary treatment. On the other hand, waiting until the child is older to decide if he is really delayed may deprive him of much needed intervention at the best possible time. Therefore, some type of instrument is needed which can assess children at a young age and predict which children are potentially normal and which children will continue to be delayed. 
The ability of intelligence tests to serve as predictors of future language development has been debated for many years. The expectation that infant intelligence tests would be predictive of language development comes from several hypotheses that claim that early nonverbal cognitive development is related to the acquisition of language (Siegel, 1981.).

\section{STATEMENT OF PURPOSE}

The purpose of this study was to examine the relationship between verbal and nonverbal indices of intelligence from an infant development scale given at approximately two years of age with scores on an expressive language test administered to the same children two years later. The children were divided into two groups. One group consisted of normal children and the other group consisted of children considered to be "late talkers." The specific questions addressed in this study are as follows :

1. Is there a difference in the number of verbal items passed at 18 to 34 months by a group of normal children and a group of late talkers?

2. Is there a difference in the number of nonverbal items passed at 18 to 34 months by a group of normal children and a group of late talkers?

3. Is there a significant relationship between nonverbal responses on an infant development test and scores on an expressive language test two years later in normal children? 
4. Is there a significant relationship between nonverbal responses on an infant development test and scores on an expressive language test two years later in normal children?

5. Is there a significant relationship between nonverbal responses on an infant development test and scores on an expressive language test two years later in late talkers?

6. Is there a significant relationship between verbal responses on an infant development test and scores on an expressive language test two years later in late talkers?

7. Is there a significant relationship between correct responses on verbal receptive items on an infant development test and scores on an expressive test two years later in normal children?

8. Is there a significant relationship between correct expressive responses on an infant development test and scores on an expressive langauge test two years later in normal children?

9. Is there a significant relationship between correct responses on verbal receptive items on an infant development test and scores on an expressive language test two years later in late talkers?

10. Is there a significant relationship between correct expressive responses on an infant development test and scores on an expressive language test two years later in late talkers?

The null hypothesis for questions one and two states that there will be no difference between the number of verbal and nonverbal items passed in the late talking and normal groups.

The null hypothesis for questions three and four states that there will be no significant correlation 
between the number of correct nonverbal and verbal responses on an infant development scale and the score on the expressive language test two years later in the normal group.

The null hypothesis for questions five and six states that there will be no significant correlation between the number of correct nonverbal and verbal responses on an infant development scale and the score on the expressive language test two years later in the group of late talkers.

The null hypothesis for questions seven and eight states that there will be no significant correlation between the correct verbal receptive and expressive responses on the infant development scale and scores on the expressive language test two years later in normal children.

The null hypothesis for questions nine and ten states that there will be no significant correlation between the correct verbal receptive and expressive responses on the infant development scale and scores on the expressive language test two years later in late talkers. (See Table I for a summary of questions.) 
TABLE I

SUMMARY OF QUESTIONS

Question

Number

1

2

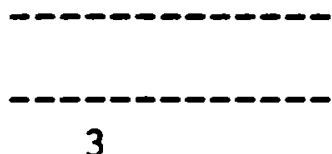

4

5

6

7

8

9

10
Significance Difference Between Groups

\# Verbal Correct

\# Nonverbal Correct
Population

Norm/Late Talkers

Norm/Late Talkers

Significant Correlation

Nonverbal/Expressive Normal

Age 2 Age 4

Verbal/Expressive

Age 2 Age 4

Normal

Nonverbal/Expressive

Age 2 Age 4

Late Talkers

Verbal/Expressive

Age 2 Age 4

Late Talkers

Verbal Recep/Expressive Normal

Age 2 Age 4

Expressive/Expressive Normal

Age 2 Age 4

Verbal Recep/Expressive Late Talkers

Age 2 Age 4

Expressive/Expressive Late Talkers

Age 2 Age 4

DEFINITION OF TERMS

The following are descriptions of specific terms

used in this study.

Cognition: A general concept embracing all of the various modes of knowing: perceiving, remembering, imagining, conceiving, judging, and reasoning (Nicolosi, Harryman, \& Kresheck, p. 55). 
Expressive Language: Use of conventional symbols to communicate one's perceptions, ideas, feelings, or intentions to others. Ability to communicate via the spoken or printed word (Nicolosi, et al., p. 129).

Language Disorder: Any difficulty with the production and/or reception of linguistic units (Nicolosi, et al., p. 130). In this study it refers to children whose language abilities are below those expected by their age and level of functioning (Shames \& Wiig, 1986).

Late Talkers: Children ages 18 to 23 months who produce fewer than 10 words, or 24 to 34 months who produce fewer than 50 words or produce no 2-word combinations.

Verbal: Pertaining to words, especially spoken words; oral expression (Nicolosi, et al., p. 253).

Nonverbal: Without oral language (Nicolosi, et al., p. 161).

Nonverbal Test: Any examination, evaluation, or measurement that does not utilize verbal material; may be administered without employing words (Nicolosi, et al., p. 161).

Object Permanence: A construct used by $\mathrm{Piaget}$ (1937/1954) to explain the series of stages that children go through in their development of the idea that objects continue to exist when out of sight (Corrigan, 1979, p. 623).

Symbolic Play: pretending that one object is another or pretending actions associated with other circumstances (Chapman \& Miller, 1980). 
CHAPTER II

\section{REVIEW OF THE LITERATURE}

During the 1970 's, the belief that cognitive development was responsible for the acquisition of language became very popular (Rice \& Kemper, 1984). But by the mid 1970's counterarguments began to appear. At the present time, cognition is still of interest in the study of language development but the approach is more conservative (Rice \& Kemper, 1984).

There are several hypotheses that claim that early cognitive development is related to the acquisition of language. The strong cognition hypothesis states that language development is completely determined by the child's cognitive development which is attained through interaction with his nonlinguistic environment (Schlesinger, 1976). Piaget believed that intelligence appeared well before language. He claimed that the development of sensori-motor operations is necessary for language development. He stated that language is seen as a facilitator of cognitive development, but not as a prerequisite necessary for the development of cognition (Wadsworth, 1979). Bowerman (1974) claims that cognition 
affects the acquisition of language in many different areas. Some abilities she believes to be necessary for normal language development include:

1. The ability to use symbols to represent objects and events that may not be perceptually-present.

2. The development of basic cognitive structures and operations.

a. The ability to order spatially and temporally.

b. The ability to classify in action.

c. The ability to embed action patterns into each other.

d. The establishment of concepts of basic invariance involving object permanence and conversation.

e. The ability to apprehend relationships between objects and action.

f. The construction of a model of perceptual space with certain properties.

3. The ability to formulate appropriate concepts or categories to serve as the structural components upon which linguistic rules can operate (p. 270).

Another hypothesis made popular in the 1970's is the local homology model. This hypothesis claims that there is simultaneous emergence of cognitive and linguistic knowledge (Rice \& Kemper, 1984). It claims that language and cognition are correlated differently at the different stages of development (Roth \& Clark, 1987). There is not a general relationship between cognition and language. 
However, there are specific relationships between cognition and language that occur at specific times (Thal, Tobias, \& Morrison, in press). These two hypotheses were strong in the 1970's and led to the development of the next three hypotheses (Rice \& Kemper, 1984).

The correlational hypothesis claims that language and cognition mutually influence each other's development. Attainment of skills can be shown first in either cognition or language (Kelly \& Dale, 1989). Schlesinger (1974) suggests that language builds on the child's developing cognitive repertoire and in turn shapes it. By learning the meaning of words, the child is able to categorize the items for which these words stand.

The weak cognitive hypothesis states that cognition is not responsible for all language development (Schlesinger, 1976). Cromer (1976), maintains that there are certain kinds of linguistic knowledge that are not accounted for by cognition. One example is language acquisition which is independent of meanings. This means a child will learn a more complex way of expressing the same idea. He will first use his proper name when referring to himself, and later will use "me" or "I."

The cognition-anchored hypothesis states that children's concepts are unstable until they are anchored with linguistic forms (Rice \& Remper, 1984). 
LANGUAGE AND COGNITION RESEARCH IN NORMAL DEVELOPMENT

These hypotheses have influenced psycholinguists to look at nonverbal cognitive strategies to explain language development. The factors that Bowerman mentioned have been examined in several studies. Several explicit predictions have been made about the relations between performance on Piagetian cognitive tasks and language acquisition in normal children. Bates, Camaioni, and Voltera (1976) suggest that the child learns the role of language in communicating his intentions and influencing others. He understands that language is a tool that may be used to manipulate and control his environment. Consequently problem-solving and understanding of cause and effect will be related to language.

Means-Ends and Word Use

Studies have shown that children who are in early stage 6 object permanence will be using single words and naming objects. By late stage 6 , the child will use twoword combinations and relational and disappearance words (Corrigan, 1979). Kelly and Dale (1989) found that children who score high in means-ends tasks are more productive speakers than those who score lower. Means-ends is defined as the ability of the child to anticipate events which are independent of those that are happening 
at that moment. The child is able to associate certain signs with an action which will follow. For example, a child will realize she must put down one object in order to pick up another (Owens, 1984). Relly and Dale (1989) showed that during symbolic play, children who have a higher level of productive language are able to join two or more play behaviors in a sequence. However, children who are at a one-word level use single elements in play activities.

Object Permanence and Word Use

According to Moore and Meltzoff (1978, cited in Siegel, 1981), the understanding of object permanence is a critical part of language development. They claim that when children realize that objects in the environment exist whether they perceive them or not, they have acquired the ability to attach labels to objects. Therefore, mastering the concept of object permanence should be related to language development.

\section{Symbolic Play and Word Use}

Owens (1984) claims that symbolic play is important for development of language. He states that there is a correlation between the number of schemes a child can handle in language and in symbolic play. 
Language and Cognition Research

Siegel (1981) administered the Bayley to 148 infants at $4,8,12,18$, and 24 months of age. She found that object permanence items were predictive of language development. She suggested that this may indicate that the ability to look for an object which has disappeared may be a precursor to language development as was predicted by Moore and Meltzoff (1978).

Corrigan (1978) conducted a longitudinal study of three children, ages 9, 10, and 11 months. She examined the relationship between object permanence and language development. She found that there was not a one-to-one relationship between object permanence and language. However, there were relations at certain points in development. Results showed a correspondence between the child's ability to search for an invisibly displaced object and the emergence of one-word utterances. Correspondence was also found between the attainment of the final rank of object permanence scale and an increase in the child's total vocabulary. She states that the increase in language growth is probably due to the increase in the child's symbolic ability necessary to perform on both tasks.

Bates, Benigni, Bretherton, Camaioni, and Volterra (1977) also conducted a longitudinal study in which they studied gestural performatives. Performatives refer to 
the act that the speaker intends to carry out with his sentence--"declaring, promising, asking questions, and so on" (p. 248). This study consisted of three infant girls aged 2,6 , and 12 months. They found that the main cognitive prerequisite for gestures is Piaget's sensorimotor stage 5 . They concluded that Stage 5 communicative events and stage 5 cognitive events should occur in about the same time period across normal children.

In a study done by Gopnik and Meltzoff (1986), the relationship between semantic and cognitive development was examined. Subjects in the study included 30 eighteen-month-old children. The children were tested on their abilities in object permanence and means-ends tasks. The parents completed a questionnaire about the child's use of relational words at home. Results of the study showed that the children who did better on the object permanence tasks used disappearance words such as "gone" more often than those who didn't do as well on the tasks. Also children who were able to solve difficult means-ends tasks were more likely to use success/failure words such as "there" and "uh-oh" than those who were not able to solve the tasks.

Gopnik and Meltzoff carried out the same study on 19 children. However, this was a longitudinal study. The children were 13 to 19 months old. They were given object 
permanence and means-ends tasks every one, two, or three weeks, depending on the subject. At each session parents were given a questionnaire to fill out. They were asked to record any relational words used by the child. This study revealed that the amount of time between the solution of the object permanence tasks, and acquisition of disappearance words, and between solution of means-ends tasks and acquisition of success/failure words was very small. There was also a strong correlation between the age of the child when he first solved object permanence tasks and the age when he first acquired disappearance words and between the age at which he first solved meansends tasks and the age at which he acquired success/ failure words.

Gopnik and Meltzoff claim that these results show that there is a strong correlation between cognitive and language development during the one-word stage. They go on to state that a child's specific cognitive abilities seem to affect the course of their early language development.

Kelly and Dale (1989) looked at the relationship between cognition and early language in 20 normal children between the ages of one and two. The children were divided into four groups consisting of no-word users, single-word users, nonproductive syntax users, and productive syntax users. The no-word users produced 
no spontaneous words during a language sample. The parents reported these children were not producing words. The single-word users produced at least one spontaneous word during a language sample. Parents reported that the child had at least five words in his vocabulary. Nonproductive syntax users produced at least two unique utterances, but they were not productive. A nonproductive utterance is one in which the child does not combine the parts of the utterance with different words. The words in the utterance are never used in isolation or in a combination with different words. Productive syntax users produced at least one productive utterance. An utterance is classified as productive if each word is grammatically free. It has to encode the same semantic relationship, occur with different words, and occupy the same position in at least two different utterances. They tested four cognitive areas. These areas included object permanence, means-ends, play, and imitation.

Results of this study showed that on symbolic play measures the no-word users scored significantly lower than the one-word users. The nonproductive syntax users produced Level 4 and 5 plays, whereas the single-word users did not. Level 4 play includes two types of behaviors. The first involves the same conventional action performed on two or more different animate actors in sequence. The second involves two or more different conventional 
actions performed in sequence on the same animate actor other than himself. Level 5 play includes four types of behavior:

a) a sequence of at least three conventional actions following the logic of a realistic scene and involving at least one animate actor;

b) object substitution;

c) search for relevant object/action;

d) prior verbal announcement" (Kelly \& Dale, p. 650).

Levels 4 and 5 were considered to be symbolic and representative of Piaget's stage 6 . The nonproductive syntax users were able to produce combinational play which is joining two or more play behaviors in a sequence. They were also able to use combinations in their language and produce Level 4 and 5 play. However, the one-word users produced single elements in both play and language.

Means-ends skills were compared in nonproductive syntax users and productive syntax users. Those children who were producing combinations of words scored higher on means-ends tasks than those whose combinations were still nonproductive.

In most of the cognitive areas, some of the children displayed language skills that were above the expected level of cognition. This evidence supports the correlation hypothesis which states that language and cognition 
are associated, but the acquisition of skills can be seen in either language or cognition.

McCune-Nicolich (1981) conducted a study on the relationship between entry into stage 6 object permanence development and the acquisition of relational words. The study consisted of five girls, ages 1.2 to 1.6 years old. These children were observed while playing with their mothers during a 30-minute free-play session. This was done every month for a period of 7 to 11 months. The child's relational words were identified and their use was described. Results showed that the emergence of relational words seemed to occur concurrently with the emergence into stage 6 object permanence development.

In a study done by Tomasello and Farrar (1984), six 12-month-old children were observed weekly for six months. They were in stage 5 object permanence when the study began. All of the children used present relational words in stage 5 object permanence. These are words that refer to the spatial change of objects/persons within the child's sight. Hi, bye, up, thank you, and uh-oh are examples of these words.

Absent-relational words are words that refer to the movement of objects or persons that occur partially or totally outside the child's field of vision. These words represent actions of objects that are present and then disappear. Examples include all gone, more, find, and 
another. None of the children used these words in stage 5. These words first appeared in stage 6 .

Tomasello and Farrar concluded that different relational words are connected to different levels of object permanence. They stated that relational words requiring the understanding of the visible movement of objects should emerge during stage 5 since this is when the child first succeeds at hiding tasks which use visible displacements. Relational words which require the concept of object movements which are not visible should not emerge until stage 6 when the child is following invisible displacements in hiding tasks.

In a later study done by Tomasello and Farrer (1986), a lexical training method was used to teach words to 23 children who were in stage 5 and 6 of object permanence development. The words they were taught referred to objects, to the visible movement of objects, and to the invisible movement of objects. They found that the children in stage 5 were able to learn at least one word which referred to visible movements. None of the stage 5 children learned an invisible movement word.

They concluded that children will not learn invisible movement words until after they enter stage 6 object permanence. They claim that the child must have some conceptual understanding of a word before the adult use of the word can be used. 
These studies support the claim that cognition and language development are related. However, there were variations in the results. Some of the research demonstrated that children had attained a certain cognitive level before acquiring a certain level of language. other studies simply demonstrated a correlation between cognition and language. The cognitive areas studied were object permanence, means-ends, play, and imitation. All of these studies demonstrate the importance of cognitive abilities in the acquisition of language.

Conflicting results also occurred in these studies. Some studies stated that children were able to use language skills which exceeded their expected level of cognition. Others claimed that the child must have some conceptual understanding of a word before the adult use of the word can be used.

These studies taken together fail to identify a definite relationship between cognition and language. Just what that relationship is is still a subject for debate. If cognition and language are related, a child with a language disorder may have some type of cognitive deficit that is affecting his ability to develop language normally. Perhaps if a cognitive deficit is suspect, this child could be tested and the deficit could be pinpointed, thus making it easier to treat the child. 


\section{COGNITION IN LANGUAGE DISORDERED CHILDREN}

A study done by Ramhi in 1981 looked at the concepts of class, number, and order in normal and language disordered children to see if their thinking and reasoning in the nonverbal area were within normal limits and to determine the importance of the symbolic function for language learning. The subjects included 10 languageimpaired children and 20 normal children. These children ranged in age from 36 to 59 months. Results of the study indicated that the language-impaired children had deficient nonlinguistic symbolic abilities. However, the findings also indicated that the nonsymbolic abilities of these children were less delayed than their linguistic abilities. Nonsymbolic abilities were tested by using the following methods. Haptic recognition consisted of the child blindly feeling geometric shapes. After feeling the shapes, the child was required to point to a visual drawing of the corresponding shape. In the water level task, the child had to draw a line indicating the level of water in a covered jar as it was rotated through five positions: $0^{\circ}, 45^{\circ}, 90^{\circ}, 135^{\circ}$, and $180^{\circ}$. In the classification task the child was required to sort geometric shapes varying in size (small and large), shape (circles, squares, and triangles), and color (red and blue). In the mental displacement task the child was 
told that a shape on the right (a horizontal line) moved over and landed on the shape on the left (a square). The child was asked to choose the correct resultant configuration. In the number conservation task, the child had to judge the relative quantity of two arrangements of checkers. Length, density, and quantity changes were made. In the linear order task, the child was to put objects in correct order in three conditions while looking at a visible model of objects. Ramhi concludes that a symbolic deficit alone was not wholly responsible for the language problems demonstrated by language-impaired children. He claims that language development requires more than knowledge about the world or the ability to represent objects and events of the world symbolically. Kamhi goes on to speculate that the combination of auditory processing problems and a deficiency in nonlinguistic symbolic abilities may be responsible for the difficulties language-impaired children encounter when acquiring language. However, no definitive conclusion can be made without further research.

In a study conducted by Johnston and Ramstad in 1982, conceptual development in seven pre-adolescent children with language impairments was examined. All of the children had normal range performance IQ. However, all of these children demonstrated obvious delays in conceptual growth. Results of the study showed that spatial 
tasks were most difficult for these children, followed by classification tasks, and finally number tasks. This study illustrates the fact that language impairment may be accompanied by cognitive deficits.

Another study done by Johnston and Weismer (1983) looked at visual imagery abilities of children with language disorders. They tested normal and language disordered first and third graders. The children were matched for sex and cognitive level. The task was to decide whether two geometric arrays were similarly ordered. The results showed that children with language disorders did not differ from normal children in accuracy of judgment or require more training trials. However, the language disordered children responded more slowly, indicating impairment of visual imagery and representational deficits which indicates a deficit in these cognitive skills.

Roth and Clark (1987) examined the relationship of symbolic play and social participation to language and cognitive development. Results showed deficits in symbolic adaptive and integrative play in children with language disorders as compared to normal children. These results support the local homologies hypothesis. Roth and clark claim that the discrepancies found between the symbolic play level and the linguistic level of the language-impaired children shows that although play and 
language seem to come from the same cognitive base, symbolic deficits are not necessarily the same across the two domains.

In 1988, Thal and Bates reported a study that looked at the relationship between language and symbolic gesture in children ages 18 to 32 months. These children were in the single-word stage of language development and were considered late talkers. Thal and Bates (1988) found a correlation between language production and gesture in the single gesture task. In this task, the child was required to produce a gesture that the examiner had modeled while speaking. For example, the examiner would hug a doll while saying "look at the baby." In this task, late talkers performed as well as their languagematched controls.

The second task required imitation of a sequence of schemes, all within a common script. Each script had four schemes and was modeled for the child. For example, feeding the teddy bear consisted of putting teddy in a chair, putting on his bib, feeding teddy an apple, and wiping teddy's mouth. In this task, the late talkers were able to produce more pairs of gestures in modeled order than the language-matched controls and were about the same as the age-matched controls. The late talkers demonstrated an ability to sequence gestural symbols before they were able to produce sequences of words. 
Thal and Bates suggest that the normal production of gestures in the second task by late talkers may have been related to their language comprehension.

Thal, Tobias, and Morrison (in press) conducted a follow-up study of Thal and Bates (1988). In this study, one year later, six of the children appeared to have caught up and four of the children were still delayed. After examining data from the first visit, Thal and Bates found that the four children who remained delayed had also been delayed in language comprehension at the first visit. The six children who caught up in production were at the same level as their age-matched controls in comprehension a year earlier. The children who remained delayed had also demonstrated poorer gestural performances in all areas than the children who caught up. Thal and Bates suggest that vocabulary comprehension may be a predictor of later expressive language delay. In addition, the connection between language comprehension and symbolic gesture production may also prove to be a good predictor of later language development.

Paul and Cohen (1984) reported a follow-up study of 20 adolescents who had been diagnosed earlier as having either developmental language disorder without social deficits or atypical developmental language disorders. Each person was given a language and cognitive evaluation made up of standardized tests. Data on the formal 
language and performance IQ tests were highly correlated. The children who had normal performance IQ's went on to develop near normal language, but children with low performance IQ's generally also showed low language performance. Even though this data may imply that performance IQ can be taken as a sufficient prediction of later language development, Paul and Cohen suggest that the overall prognosis for these children is "quite guarded." They state that although children with a high performance IQ can eventually master the basic skills for syntax, some language and learning problems will still remain. In 1984, Aram, Ekelman, and Nation conducted a longitudinal study on 20 adolescents who had originally been studied 10 years earlier as preschoolers with language disorders. Of all the measures used when they were preschoolers, The Leiter International Performance Scale was the best single predictor of language in adolescence. Their data showed that early nonverbal intelligence scores were strongly related to intelligence, class placement, academic achievement, and language intervention ten years later.

Siegel conducted a study in 1981 in which she found that the scores on The Bayley Scale of Infant Development were significantly correlated with cognitive and language scores at two years old. 
A longitudinal study done by Bishop and Edmundson in 1987 revealed a strong relationship between scores on The Leiter International Performance Scale and language outcome. They found that when a four-year-old child with a language delay also had a low nonverbal test score, prognosis was poor. These children were usually placed in special classes in school and remained delayed in their language development. However, the children who had a delay in language but a nonverbal score in the normal range generally had a better prognosis.

These studies support the claim that language deve1opment and cognition are related. In all of the above studies, children with a deficit in language also showed some type of deficit in their cognitive abilities. These deficits were found in spatial tasks, classification tasks, symbolic play, number tasks, visual imagery, and representational deficits. Since these cognitive tasks may be related to language ability, testing a child for cognitive development at a young age may be a good predictor of that child's later language development.

Intelligence tests as a predictor of future language development has been debated for many years (Siegel, 1981). The studies reviewed thus far have demonstrated a relationship between language and cognition, specifically object permanence, means-ends, play, and imitation. since these cognitive tasks are thought to be related to 
language development, testing a child's cognitive abilities on an intelligence test at a young age may be a good predictor of the child's later language development. 
CHAPTER III

METHODS AND PROCEDURES

METHODS

Subjects: Description at Intake

This study included 51 children who were part of a longitudinal study being conducted at portland state University. These children were between the ages of 18 and 34 months of age at the time of intake. They were divided into two groups. One group of 25 children was defined as a control group and the second group of 26 was identified as "late talkers" who were slow in their expressive language development. Late talkers were defined as those children who at age 18 to 23 months produced fewer than 10 words, or 24 to 34 months produced fewer than 50 words or no 2-word combinations by parent report on the Language Development Survey (Rescorla, 1989). The control group had expressive vocabulary levels that exceeded the above criteria. The Language Development Survey (LDS) is a vocabulary checklist designed to identify children with a language delay at about two years of age. The list consists of 309 different words which are arranged in 14 semantic categories. 
This checklist can be completed by a parent in about ten minutes. Rescorla (1989) conducted a series of four studies of the LDS which indicated that reliability, validity, sensitivity, and specificity for identifying language delay in toddlers are excellent using this instrument.

The subjects were obtained from three sources as a part of a longitudinal study being conducted at portland State University:

(1) Parents who were taking their children in for well-baby check-ups in three pediatric clinics in the greater Portland area were asked to fill out questionnaires concerning their child's expressive language development. These clinics included Kaiser Permanente Beaverton, Kaiser Permanente Health Center East, and The Metropolitan Clinic.

(2) Parents who responded to a radio broadcast requesting children with expressive language delays filled out the same questionnaire.

(3) Parents who responded to a newspaper article in the Oregonian requesting subjects for a study at Portland State University also filled out these questionnaires.

\section{Screening}

The following eligibility criteria were used in the selection of the subjects: 
(1) Each subject passed a speech reception screening at $25 \mathrm{~dB}$ using visual reinforcement paradigm. This screening was administered at Portland State University by a graduate student supervised by an audiology instructor or the audiology instructor himself.

(2) Each child scored 85 or higher on The Bayley Scale of Infant Development.

(3) The control group was matched to the late talkers group on the basis of race and socio-economic status (see Table II).

\section{TABLE II}

SUMMARY OF DEMOGRAPHIC DATA

Mean Age in Months

Group When Test Was Administered

$\underline{\text { SES }}$

Race

Normal

LDS

Bayley

TOLD

24.56

26.04

2.52 *

968 White

48 Minority

Delayed

LDS

Bayley

TOLD

25.69

$2.73 * 1008$ White

*Based on a scale of 1 to 5 with 1 being the highest socio-economic status and 5 being the lowest.

The nature of the study was explained both orally and in writing to the parents. Parents were asked to sign a written permission form for participation in the study. 
Follow-Up Assessment

At approximately four years of age, the children were assessed for expressive language development using The Test of Language Development. Spoken language composite scores were calculated for each subject at age four. Correlations between verbal and nonverbal scores on the last 40 Bayley items and expressive language outcome on the TOLD were computed. The number of verbal and nonverbal items passed by each group was also compared.

\section{Instruments}

The Bayley Scale of Infant Development. This is a test designed to measure a child's development in the first two-and-one-half years of life. The test is made up of three parts:

(1) Mental scale: assesses sensory-perceptual abilities and discriminations. It also tests object permanence, memory, learning, and problem-solving abilities. It tests verbal communication and the beginnings of abstract thinking.

(2) Motor scale: assesses the amount of coordination the child has in both gross and fine motor skills.

(3) Infant behavior record: assesses the child's social adjustment to his environment. 
The mental scale was the only portion of the test administered. Reliability coefficients for the mental scale of the Bayley, according to the test manual, range from .81 to .93 with a median value of .88 . Validity was not discussed in the manual.

The Bayley consists of 163 items. All subjects tested passed all items on the Bayley up to item 123; therefore, performance on items 124 through 163 only will be reported here.

The Test of Language Development (TOLD) was designed to compare a child's expressive language abilities with those of his peers. It also compares the child's abilities across the different expressive areas. The TOLD has five principal expressive subtests. They include picture vocabulary, oral vocabulary, grammatic understanding, sentence imitation, and grammatic completion. The TOLD manual provides a method for deriving a spoken language quotient which is a composite of the foregoing expressive subtest score. This composite score was used as the outcome measure. According to the test manual, the TOLD is a very reliable test with an internal consistency of .80 and stability reliability of .99. Content, criterionrelated, and construct validity were all reported in the manual as adequate. 


\section{PROCEDURES}

Each subject meeting subject and screening criteria was given The Bayley Scale of Infant Development at approximately two years of age by a trained psychologist at Portland State University. All subjects tested passed all items on the Bayley up to item number 123. For this reason, only the last 40 items on the Bayley were examined. Of these, 21 are verbal items. The expressive items are: $124,127,130,136,138,141,145,146,149$, and 150. The first three expressive items require the child to name an object in order to get credit for that question. The following expressive items require the child to name objects and pictures, ranging from two to five items. The receptive items are: $126,128,131$, $132,139,144,148,152,158,162$, and 163. The receptive items require the child to point to pictures or follow directions given by the administrator. The other 19 questions are nonverbal. They are: 123, 129, 133, $134,135,137,140,142,143,147,151,153,154,155$, $156,157,159,160$, and 161. These nonverbal items require the child to place pegs in a board in a certain amount of time, imitate coloring, and placement of blocks. The number correct of the last 21 verbal items is the child's verbal score. The last 20 nonverbal items will be used as the child's nonverbal cognitive score. 
At approximately four years of age the children were assessed for expressive language development using The Test of Language Development. Spoken language composite scores were calculated for each subject at age four. Correlations between verbal and nonverbal scores on the last 40 Bayley items and expressive language outcome on the TOLD were computed.

\section{STATISTICAL ANALYSIS}

The Pearson-Product-Moment-Correlation coefficient was used to determine the relationship between the number of correct verbal and nonverbal responses on The Bayley Scale of Infant Development and the expressive language scores on The Test of Language Development. This was used to determine if there is a relationship between the two scores of the normal group and the two scores of the delayed group. It was also used to determine if there is a relationship between verbal receptive items and expressive responses on the infant development scale and the scores on the expressive test two years later in both groups.

A $t$-test was used to compare the number of verbal and nonverbal items passed by each group. 


\section{CHAPTER IV \\ RESULTS AND DISCUSSION}

RESULTS

The first two questions posed in this study concern whether there is a difference between the number of verbal and nonverbal items passed by the normal group and the late talking group on the infant development test at 18 to 34 months. Two one-tailed $t$-test for independent means were used to determine if there was a statistically significant difference between the number of verbal and nonverbal items passed in the two groups. These tests showed that as expected, the normals passed significantly more verbal items, but the difference between groups on nonverbal items failed to reach signficance (see Table III).

\section{TABLE III}

MEAN SCORES, STANDARD DEVIATIONS AND $T$-VALUES FOR RESPONSES IN NORMAL GROUP AND LATE TALRERS

Verbal

Normal

Late Talkers

Nonverbal

Normal

Late Talkers
Mean

17.40

10.57

15.48

14.15
$\underline{S D}$

5.15

4.98

3.50

4.65 df

24

4.77 *

*Significant beyond the .05 level of confidence. 
Questions three through six ask if there is a significant relationship between nonverbal and verbal scores on the infant development test and scores on the expressive language test two years later. The Pearson-ProductMoment Coefficient of Correlation (Pearson $r$ ) was used to determine strength of the association between the correct verbal and nonverbal responses and the score on the expressive language test for each group. The strength of the association is shown in Table IV.

\section{TABLE IV}

PEARSON $r$ COEFFICIENT OF CORRELATION BETWEEN CORRECT NONVERBAL AND VERBAL RESPONSES AT AGE TWO WITH THE SCORE ON THE EXPRESSIVE LANGUAGE TEST TWO YEARS LATER FOR ALL SUBJECTS

Normal Group

Nonverbal

Verbal

Pearson $r$

p

.28

.25

NS

NS

Late Talkers

Nonverbal

Verbal

.25

.39

NS

*Significant relationship.

These results indicate that there is a small but significant relationship between correct verbal responses on the infant development scale and the expressive score two years later in the group of late talkers. These results show no significant relationship between the correct nonverbal responses on the infant development test and the expressive score two years later in the group of 
late talkers. There was also no significant relationship between correct verbal and nonverbal responses on the infant development scale and the expressive score two years later in the control group.

Question seven asks if there is a significant relationship between the number of correct responses on verbal receptive items and scores on an expressive language test two years later in the normal group. Question eight asks if there is a significant relationship between the number of correct expressive responses on an infant development test and scores on an expressive language test two years later in the normal group. The PearsonProduct-Moment Coefficient of Correlation (Pearson $r$ ) was used to determine the association. The strength of the association is shown in Table $V$. These results indicate no significant relationship.

\section{TABLE V}

PEARSON $\mathrm{r}$ COEFFICIENT OF CORRELATION BETWEEN CORRECT RESPONSES ON VERBAL RECEPTIVE ITEMS AND CORRECT EXPRESSIVE RESPONSES ON INFANT DEVELOPMENT TEST WITH SCORES ON EXPRESSIVE LANGUAGE TEST TWO

YEARS LATER IN NORMAL CHILDREN

Responses

Verbal Receptive Items Expressive Responses
Pearson $r$ p

NS NS

Question nine asks if there is a significant relationship between the number of correct responses on 
verbal receptive items and scores on the expressive language test two years later in late talkers. Question ten asks if there is a significant relationship between the number of correct expressive responses on the infant development test and scores on the expressive language test two years later in late talkers. The PearsonProduct-Moment Coefficient of Correlation (Pearson $r$ ) was used to determine the association. The strength of the association is shown in Table VI. These results indicate that there is a significant relationship between the number of verbal receptive items correct and the expressive score two years later at the .001 level of confidence. However, no significance was reached for the expressive responses.

\section{TABLE VI}

PEARSON $r$ COEFFICIENT OF CORRELATION BETWEEN CORRECT RESPONSES ON VERBAL RECEPTIVE ITEMS AND CORRECT EXPRESSIVE RESPONSES ON INFANT DEVELOPMENT TEST AND SCORES ON EXPRESSIVE LANGUAGE TEST TWO YEARS LATER IN LATE TALRERS

Responses

Verbal Receptive Items Expressive Responses
Pearson $\mathbf{r}$

.61

.25
D $.001 *$ NS

*Significant relationship.

In summary, the data of this study indicate a significant difference between the number of correct verbal items passed on the infant development scale, but no 
significant difference between the number of nonverbal items passed between the two groups.

A significant relationship was found between correct verbal responses on the infant development scale and the expressive test two years later in the group of late talkers. Nonverbal responses in the group of late talkers failed to reach significance. No significance was found in either verbal or nonverbal responses on the infant intelligence test and the expressive test two years later in the normal group.

There was a significant relationship found between the verbal receptive items on the infant development scale at two years old and the expressive language score at four years old in the group of late talkers. Other correlations failed to reach significance.

\section{DISCUSSION}

The purpose of this study was to investigate whether there was a significant relationship between verbal and nonverbal responses on an infant development test at two years of age with scores on an expressive language test at four years of age. This study also looked at the difference in the number of correct verbal and nonverbal items in the group of late talkers and the control group of normal children. 
The results of this investigation revealed that, as expected, the normal children passed significantly more verbal items than the group of late talkers. However, the difference between the groups on nonverbal items failed to reach significance. This indicates nonverbal skills in the group of late talkers are comparable to those skills in their normally speaking peers. Thus, late talking cannot be seen as a result of general depression in intellectual development and would appear to reflect some specific deficit in linguistic skills.

Data from this study also revealed a significant relationship between the number of correct verbal responses at age two and expressive language scores at age four in the group of late talkers. No significance was shown between correct nonverbal responses at age two and expressive language scores at age four in the group of late talkers. This data does not support the notion that nonverbal cognitive skills lead the way for language development in the early years. Rather, they lend more support to the correlational or weak forms of the cognitive hypothesis, rather than the strong form. As stated earlier, the strong cognition hypothesis states that language development is completely determined by the child's cognitive development, whereas the correlational hypothesis claims that language and cognition mutually influence each other's development. 
A significant relationship was found between the number of correct verbal receptive responses on the infant intelligence test and expressive skills at age four but no significant relationship between the number of correct expressive responses on the infant intelligence test and expressive scores on the TOLD for late talkers. These results agree with the results of the study done by Thal, Tobias, and Morrison (in press). In their longitudinal study, they found that children who were delayed in their gestural and expressive skills, but had normal comprehension skills, eventually caught up with their age-equivalent peers in their expressive skills. Those who were also delayed in their comprehension remained delayed in their comprehension and expressive skills. This study supports the notion that early receptive skills predict later expressive ability better than early expressive skills themselves.

There was no relationship between verbal receptive or expressive items at age two and language skills at age four in the normal group. This may be interpreted to mean that as a group overall, they are functioning at ageappropriate levels. In normal functioning children an age-appropriate level is quite variable in the relative strength of their verbal and nonverbal skills. These children can still be classified as normal with a broad range of levels of each, so their verbal skills at an 
early stage aren't strongly tied to language skills later because the range of normal is so broad. However, for later talkers comprehension does predict later language development because as stated earlier, it lays a foundation for the development of expressive skills. Without that basic foundation, the expressive skills can't grow, no matter how strong or weak they were at the outset. That may be the reason there is no relationship between early and later expressive levels in the normal group. 


\section{CHAPTER V}

\section{SUMMARY AND IMPLICATIONS}

\section{SUMMARY}

Language delay is the most prevalent developmental problem found in school children (Bax, Hart, \& Jenkins, 1980). Since small children acquire language at such varying degrees, it is difficult to know the best age for identifying a language disorder. Therefore, some type of instrument is needed which can assess children at a young age and predict which children are potentially normal and which children will continue to be delayed.

The purpose of this study was to examine the relationship between verbal and nonverbal indices of intelligence from an infant development scale given at approximately two years of age and scores on an expressive language test administered to the same children at four years of age. The questions this study sought to answer were: is there a difference in the number of verbal and nonverbal items passed between the group of normal children and the group of later talkers; is there a significant relationship between nonverbal and verbal scores on 
an infant development test and scores on an expressive language test two years later; is there a significant relationship between correct responses on verbal receptive items and correct expressive responses on an infant development test and scores on an expressive language test in normal children; and is there a relationship between correct responses on verbal receptive items and correct expressive responses on an infant development test and scores on an expressive language test in late talkers.

Subjects consisted of 51 children between the ages of 18 and 34 months of age. They were divided into two groups: one group of late talkers and a second group of normal children. Subjects were obtained from three sources as a part of a longitudinal study being conducted at Portland State University.

The instruments used to acquire the data for this study were The Language Development Survey, Bayley Infant Development Scale, and The Test of Language Development. The subjects were administered the Bayley Infant Development Scale at approximately two years of age and The Test of Language Development at approximately four years of age.

In answering the first two questions posed, results of a one-tailed $\underline{t}$-test for independent means indicated a significant difference in the number of verbal items passed at age two by the control group and the late 
talkers. No significant difference was found in the number of nonverbal items passed at age two by the group of normal children and the group of late talkers.

The Pearson-Product-Moment Correlation $r$ was used to answer the remaining questions. The results for questions three and four indicate that there is no significant relationship between nonverbal responses and scores on the expressive langauge test at the .05 level of confidence in either group. There was also no significant relationship indicated between correct verbal responses on The Infant Development Scale and the expressive test two years later in the normal group. However, there was a small but significant relationship between correct verbal responses and scores on the expressive language test at the .05 level of confidence in the group of late talkers. The results for questions five and six found no significant relationship. When looking at the results of questions seven and eight, it was found that there was a significant relationship on verbal receptive items at the .001 level of confidence. However, no significance was reached for the expressive responses.

\section{CLINICAL IMPLICATIONS}

Results of this study indicate that there is a significant relationship between the verbal receptive items on the infant development scale at two years old and the 
expressive language score at four years old in late talkers, but not for the group of normal children.

These results may indicate that the infant development scale could be used as a predictor to tell us whether a child who is considered a late talker at two years old will continue to be disordered or delayed at four years old. If the child responds well on the verbal receptive items at two years old, he may prove to be a late talker. However, if he does not score well at two years of age, perhaps further testing is warranted. The infant development scale may be a good instrument for screening young children. However, this leads to several unanswered questions. Is there value in intervention at such a young age? Would intervention prove to be effective at this age? Could this possibly be of value to lower the case load numbers in public schools? Would it be cost effective?

\section{RESEARCH IMPLICATIONS}

Further research into the question of expressive language scores on the infant development scale as a predictor of later language development needs to be done. Some questions that could be addressed may include: were the late talking children a good representation for children with a language problem; is the Bayley the best choice for measuring the nonverbal skills of two year 
olds; are the Bayley and TOLD a good pair of tests to predict expressive language or are there better tests to use; what type of training would be required to administer the tests; would only a developmental test be valid or would other language tests be effective; do infant development tests really measure the child's cognitive development or just his ability to communicate his thoughts; is the Bayley score predictive of later IQ; are the Bayley language items predictive of later verbal $I Q ;$ are the Bayley nonverbal items predictive of later nonverbal IQ; and does comprehension training predict later expressive skills in late talkers as these results suggest they should. 
REFERENCES

Aram, D.M., Ekelman, B.L., and Nation, J.E. (1984). Preschoolers with language disorders: 10 years later. Journal of Speech and Hearing Research, 27, 232-244.

Bates, E., Camaioni, L., and Volterra, V. (1976). Sensorimotor performatives. In E. Bates, Language and Context: The Acquisition of Pragmatics. Academic Press: New York.

Bates, E., Benigni, L., Bretherton, I., Camaioni, L., and Volterra, V. (1977). From gesture to the first word: On cognition and social prerequisites. In M. Lewis and L.A. Rosenblum (eds.), Interaction, Conversation, and the Development of Language. John Wiley \& Sons: New York.

Bax, M., Hart, H., and Jenkins, S. (1980). Assessment of speech and language development in the young child. Pediatrics, $66,350-354$.

Bishop, D.V.M., and Edmundson, A. (1987). Languageimpaired 4-year-olds: Distinguishing transcient from persistent impairment. Journal of Speech and Hearing Disorders, $\underline{52}, 156-17 \overline{3}$.

Bowerman, M. (1974). Discussion summary: Development of concepts underlying language. In R.L. Schiefelbusch and L.L. Lloyd (eds.), Language PerspectivesAcquisition, Retardation, and Intervention, pp. 191-209. University Park Press: Baltimore.

Chapman, R.S., and Miller, J.F. (1980). Analyzing language and communication in the child. In $R$. Schiefelbusch (eds.), Nonspeech Language and Communication, Analysis and Communication. University Park Press: Baltimore.

Corrigan, R. (1978). Language development as related to stage 6 object permanence development. Journal of Child Language, $\underline{5}, 173-189$. 
Corrigan, R. (1979). Cognitive correlates of language: Differential criteria yield differential results. Child Development, 50, 617-631.

Cromer, R.F. (1976). The cognitive hypothesis of language acquisition and its implications for child language deficiency. In R.L. Schiefelbusch and L.L. Lloyd (eds.), Normal and Deficient Child Language. University Park Press: Baltimore.

Gopnik, A., and Meltzoff, A.N. (1986). Relations between semantic and cognitive development in the one-word stage: The specificity hypothesis. Child Development, 57, 1040-1053.

Johnston, J.R., and Ramstad, V. (1982) . Cognitive development in pre-adolescent language impaired children. British Journal of Disorders of Communication, 18, 49-55.

Johnston, J.R., and Weismer, S.E. (1983). Mental rotation abilities in language disordered children. Journal of Speech and Hearing Research, 26, 397-403.

Kamhi, A.G. (1981). Nonlinguistic symbolic and conceptual abilities of language-impaired and normally developing children. Journal of speech and Hearing Research, 24, 446-453.

Kelly, C.A., and Dale, P.S. (1989). Cognitive skills associated with onset of multiword utterances. Journal of speech and Hearing Research, 32, 645-656.

McCune-Nicolich, L. (1981). The cognitive bases of relational words in the single word period. Journal of Child Language, $\underline{8}, 15-34$.

Nicolosi, L., Harryman, E., and Rresheck, J. (1983). Terminology of Communication Disorders. Waverly Press, Inc. : Baltimore.

Owens, R.E. (1984) - Language Development. Charles E. Merrill Publishing Co.: Columbus.

Paul, R., and Cohen, D.J. (1984). Outcomes of severe disorders of language acquisition. Journal of Autism and Developmental Disorders, $\underline{14,405-\overline{42} 1}$.

Rescorla, L. (1989). The language development survey: A screening tool for delayed language in toddlers. Journal of Speech and Hearing Disorders, 54, 587-599. 
Rice, M.L. (1983). Contemporary accounts of the cognition/language relationship: Implications for speech-language clinicians. Journal of Speech and Hearing Disorders, $48,347-359$.

Rice, M.L., and Kemper, S. (1984). Child Language and Cognition. Pro-Ed: Austin.

Roth, F.P., and Clark, D.M. (1987). Symbolic play and social participation abilities of language-impaired and normally developing children. Journal of speech and Hearing Disorders, 52, 17-29.

Schlesinger, I.M. (1974). Relational concepts underlying language. In R.L. Schiefelbusch and L.L. Lloyd (eds.), Language Acquisition and Intervention. University Park press: Baltimore.

Schlesinger, I.M. (1976). Cognitive development and linguistic input. Child Development, 47, 153-169.

Shames, G.H., and Wiig, E.H. (1986). Human Communication Disorders. Charles E. Merrill Publishing Co.: Columbus.

Siegel, L.S. (1981). Infant tests as predictors of cognitive and language development at 2 years. Child Development, ⒉ 232-244.

Thal, D., and Bates, E. (1988). Language and gesture in late talkers. Journal of Speech and Hearing Disorders, $31, \overline{115-123}$.

Thal, D., Tobias, S., and Morrison, D. (in press). Language and gesture in late talkers: A one year follow-up. Journal of Speech and Hearing Disorders.

Tomasello, M., and Farrar, M.J. (1984). Cognitive bases of lexical development: object permanence and relational words. Journal of Child Language, 11, 477-493.

Tomasello, M., and Farrar, M.J. (1986). Object permanence and relational words: A lexical training study. Journal of Child Language, 13, 495-505.

Wadsworth, B.J. (1979). Piaget's Theory of Cognitive Development. Longman, Inc.: New York. 